\title{
LIÑAXES MASCULINAS EN GALICIA DENDE UN PUNTO DE VISTA XENÉTICO E IMPLICACIONS HISTÓRICAS E CULTURAIS
}

Maria Brión, Paula Sänchez-Diz

Unidade de Xenética. Instituto de Medicina Legal (USC)

O ADN humano está formado por 3000 millóns de pares de bases e unicamente un $0,1 \%$ destas bases son diferentes en dúas persoas tomadas ao azar da poboación. Se en lugar de individuos consideramos poboacións, só un $10 \%$ das diferenzas xenéticas totais poden ser explicadas por diferenzas entre grandes grupos continentais e un $5 \%$ por diferenzas entre poboacións dun mesmo continente.

Polo tanto, as poboacións humanas están compostas de individuos xeneticamente diferentes e da medida desta variabilidade encárgase a xenética de poboacións.

O compoñente xenético das poboacións actuais é o resultado de diversas forzas evolutivas, influenciadas pola historia demográfica da poboación en si, as características da rexión do xenoma estudada e a interacción entre o xenoma e os factores ambientais. De xeito que se seleccionamos unha zona do xenoma non influenciada por factores ambientais con características coñecidas, podemos reconstruír a historia demográfica a partir da diversidade xenética.

\section{O CROMOSOMA Y}

$\mathrm{O}$ cromosoma $\mathrm{Y}$ é un dos cromosomas humanos máis pequenos, mide aproximadamente 60 millóns de pares de bases $(\mathrm{Mb})$, e non é esencial para a vida dun ser humano pois os homes téneno pero as mulleres non. A metade do cromosoma está formado por ADN repetido en tándem (ADN satélite), o resto presenta 
moi poucos xenes funcionais, e a maioria do cromosoma non recombina. Non obstante, son estas características especiais as que fan deste cromosoma unha ferramenta moi útil para o estudo da evolución humana recente, dende unha perspectiva masculina.

A pesar de ser morfoloxicamente distintos, os cromosomas $\mathrm{X}$ e Y emparéllanse durante a meiose e son capaces de intercambiar secuencias dentro das pequenas rexións de homoloxía que posúen. Estas rexións denominanse rexións pseudoautosomais, debido a que nelas non existe unha herdanza estritamente ligada ao sexo, e nos nosos cromosomas sexuais existen duas: a rexión pseudoautosomal maior (PAR 1) e a rexión pseudoautosomal menor (PAR 2).

\section{Caracteristicas de herdanza do cromosoma $Y$}

O ADN do cromosoma Y presenta unha herdanza paterna, na súa gran maioría haploide (non presenta unha copia homóloga. coma o resto dos cromosomas). A falta de recombinación na maior parte do cromosoma provocou que este se comporte como un fragmento único de ADN portador dun haplotipo, que se transmite intacto de pais a fillos, a non ser que algún evento mutacional teña lugar. Deste xeito, cada cromosoma Y contén unha gravación de todos os eventos mutacionais acontecidos ao longo da historia e posibilita a reconstrución das liñaxes paternas dos cromosomas $\mathrm{Y}$ actuais, co fin de atopar un devanceiro común (Jobling e Tyler-Smith, 1995).

A poboación efectiva de cromosomas $Y$, que é o número de cromosomas que pasan á descendencia nun momento determinado, é claramente inferior á dos cromosomas $\mathrm{X}$ ou calquera outro cromosoma autosómico, de xeito que nunha poboación diploide cada cromosoma Y atópase nun cuarto da frecuencia de cada cromosoma autosómico. Ademais as actividades que historicamente estiveron asociadas ao xénero masculino, como as guerras, expansións e certas estruturas sociais como a poligamia, provocaron unha diminución maior do número efectivo de cromosomas $Y$. Con todo isto, procesos evolutivos como a deriva xenética tiveron un efecto moito máis notorio sobre o cromosoma Y que sobre cal- 
quera outro, facendo moi interesante este cromosoma para o estudo de poboacións próximas xeograficamente que diverxeron en tempos recentes.

Debido a todas estas características, o cromosoma Y contribuiu enormemente aos estudos evolutivos humanos, provocando un incremento no número de traballos con diferentes tipos de polimorfismos.

\section{POLIMORFISMOS DO CROMOSOMA Y}

Os marcadores descritos inclúen polimorfismos con moi distintas caracteristicas e moi distintas taxas de mutación, co que dun modo xeral poderiamos agrupalos nas seguintes categorías:

- Polimorfismos binarios

- Microsatélites

- Minisatélites

- Satélite alfoide

Cada unha destas categorias engloba distintos tipos de polimorfismos, que a continuación se describen:

\section{Polimorfismos binarios}

Os marcadores binarios foron descritos como os polimorfismos máis frecuentes tanto no cromosoma $\mathrm{Y}$ coma no resto dos cromosomas. Eventos mutacionais como as substitucións de bases, as insercións, deleccións ou duplicacións son extremadamente raros como para que se dean unha única vez na evolución. de xeito que dan lugar aos polimorfismos bialélicos, que unicamente presentan, como o seu nome indica, dous alelos posibles, un ancestral e outro derivado ou mutado (YCC, 2002).

Entre os distintos tipos de marcadores binarios, as substitucións de bases ou SNPs ("Single Nucleotide Polymorphisms") son as mais frecuentes e atractivas debido á súa abundancia, estabilidade e simplicidade. 


\section{Microsatélites ou STRs}

Os STRs (Short Tandem Repeats) son secuencias repetidas en tảndem de pequeno tamaño que xeran polimorfismos multialélicos dependendo do número de repeticions que se presenten.

Os microsatélites do cromosoma Y posúen uns niveis de polimorfismo bastante baixos cando se comparan cos autosómicos, pero o uso en conxunto deles proporciónanos haplotipos altamente informativos que son de grande utilidade, tanto para casos forenses coma para a análise de migracións, asentamentos ou estruturas sociais das poboacións humanas (Gusmão et al., 2000).

\section{Minisatélites}

Os minisatélites tamén son secuencias repetidas en tándem pero dun maior tamaño. Actualmente existen no cromosoma Y dous locus minisatélites descritos: MSY1 (DYF155S1) e MSY2 (DYS440),

O minisatélite MSY1 (Jobling e cols., 1998) é o marcador máis variable descrito no cromosoma Y, o minisatélite MSY2, descrito recentemente, presenta unha diversidade moi baixa.

\section{Satèlite alfoide}

$O A D N$ alfoide no cromosoma $Y$, igual ca noutros cromosomas, sitúase no centrómero. Este ADN, co uso de distintas encimas de restrición, permitenos identificar patróns moi diferentes que axudan a definir determinadas liñaxes paternas.

A variación deste tipo de marcador débese a mutacións puntuais e insercións/deleccións. O satélite alfoide é un marcador moi variable, pero na súa maioria os métodos utilizados para a análise non son suficientemente robustos. 


\section{APLICACIONS ANTROPOLOXICAS DO CROMOSOMAY}

As propiedades especificas do cromosoma Y fano especialmente interesante para a xenética de poboacións xa que, ao non presentar recombinación na maior parte da súa lonxitude, este cromosoma pasa directamente de pais a fillos sen ningún cambio, excepto as diversas mutacións que poidan ocorrer.

Debido a estas caracteristicas, en principio, seria posible reconstruir a historia das linaxes paternas das poboacións estudando os polimorfismos dos cromosomas $\mathrm{Y}$ actuais. Estes estudos, na actualidade, están proporcionando unha moi útil información sobre a evolución humana, a cal complementa estudos previos realizados co ADN mitocondrial e con marcadores autosómicos.

Os polimorfismos descritos ata o momento no cromosoma $\mathrm{Y}$ inclúen sistemas con mecanismos e taxas de mutación moi diferentes, que nos permiten estudar a evolución das poboacións humanas a distintas escalas de tempo.

Os polimorfismos binarios son os que presentan as taxas de mutación máis reducidas, é dicir, os que evolucionan dunha forma máis lenta, e como tales son os marcadores de elección para estudos evolutivos antigos (Jobling e Tyler-Smith, 1995, 2003; Underhill e cols., 2000), O emprego destes polimorfismos lentos, cuxos alelos normalmente xorden unha soa vez ao longo da evolución, permitenos definir liñaxes de cromosomas que están relacionados por descendencia e que reciben o nome de haplogrupos.

Os locus microsatélites son marcadores con taxas de mutación máis elevadas, o cal posibilita a capacidade de resposta a cuestións evolutivas máis recentes.

En último lugar temos os locus minisatélites, que no caso do MSYl é o marcador do cromosoma Y con maior taxa de mutación e cunha variabilidade enorme pero, ademais, debido á súa estrutura en bloques de unidades repetitivas, ofrécenos a posibilidade de definir linaxes de cromosomas.

No caso do novo minisatélite MSY2, o nivel de variabilidade semella ser intermedio entre os marcadores binarios e os locus 
microsatélites, pero na actualidade aínda non existen estimacións da taxa de mutación nin estudos poboacionais.

A combinación destes marcadores para realizar estudos evolutivos humanos aínda acentúa máis o interese do cromosoma $Y$ para tal fin xa que, ao non existir recombinación, a evolución de cada un destes polimorfismos non é independente, senón que un cambio en calquera locus sempre acontece nun fondo xenotipico doutros locus, aos que sempre estará ligado.

O emprego dos marcadores lentos, como os polimorfismos binarios, permitenos definir unha xenealoxia de haplogrupos ou grupos de cromosomas relacionados por descendencia, dentro de cada un deles podemos estudar a variabilidade empregando marcadores máis rápidos, como os STRs ou o minisatélite MSY1, os cales. debido á súa maior taxa de mutación, nos resolven cuestións evolutivas máis recentes. Deste xeito, reduciremos o efecto das posibles mutacións recorrentes dos marcadores moi variables e obteremos unha resolución da filoxenia do cromosoma $Y$ a diferentes niveis.

Actualmente existe tal multitude de traballos publicados sobre estudos poboacionais empregando todo tipo de marcadores do cromosoma $\mathrm{Y}$ que sería moi complicado citalos todos. Resaltando o importante papel que tiveron estes traballos para resolver cuestions sobre a orixe da linaxe masculina nalgunhas poboacións e tamén sobre como ocorreron os poboamentos de diferentes zonas xeográficas, podemos nomear a modo de exemplo algúns traballos como: o estudo sobre a contribución masculina europea na Polinesia (Hurles e cols., 1998), a detección da existencia de fluxo xénico na Península Ibérica a través da barreira lingüistica entre cataláns e vascos (Hurles e cols., 1999), o estudo de poboacións norteafricanas (Bosch e cols., 1999) e, por último, o estudo do cromosoma $\mathrm{Y}$ de diversas poboacións da Península Ibérica (Brión e cols., 2003). 
Galicia está localizada no extremo noroeste da Peninsula Ibérica, polo tanto na punta máis occidental de Europa. Esta rexión ocupa aproximadamente $30000 \mathrm{~km}^{2}$ e soportou un certo illamento do resto da península, mantendo a súa propia identidade cultural (Vázquez Varela, 1993) xa que ao longo dos anos sufriu unha alta taxa de emigración pero moi baixa inmigración.

A poboación fórmana aproximadamente tres millóns de persoas, das que ao redor dun millón viven nas grandes cidades e os outros dous millóns viven en pequenas vilas ou aldeas situadas en zonas rurais e repartidas todo ao longo da comunidade.

A análise da variabilidade dos polimorfismos do cromosoma Y en Galicia realizouse baseándose en dúas mostras poboacionais diferentes, por un lado estudouse a variabilidade de individuos pertencentes na súa gran maioría aos núcleos urbanos máis importantes e por outro a variabilidade en zonas rurais dispersas por toda a comunidade.

\section{Estudo nas zonas rurais}

Na zona rural estudáronse un total de 292 individuos pertencentes a 8 comarcas diferentes que inclúen un total de 75 localidades dispersas por toda a superficie da rexión (Figura 1).

$\mathrm{Na}$ mostra rural estudáronse tanto os polimorfismos binarios como os locus microsatélites e comprobouse a existencia dunha grande homoxeneidade ao longo da comunidade, de maneira que non se atoparon diferenzas significativas na variabilidade do cromosoma $\mathrm{Y}$ entre as localidades nin entre as comarcas, pero o que si se atopou foi unha elevada diversidade dentro de cada unha destas comarcas.

Unha posible explicación á existencia desta homoxeneidade seria que ao longo da historia os homes, que son os portadores do cromosoma $\mathrm{Y}$, puideron ter unha gran mobilidade entre as distintas comarcas ou con outras zonas da península, provocando a aparición 


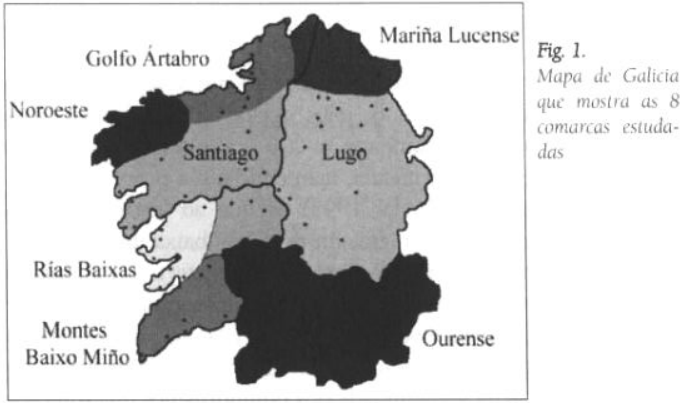

das mesmas linaxes de cromosomas todo ao longo da comunidade e, polo tanto, a falta dunha subestruturación poboacional.

Esta hipótese sobre unha maior mobilidade dos homes que das mulleres coincide cunha estrutura tipicamente matriarcal, como existe dende hai moitos anos na sociedade rural galega. Deste xeito, segundo a tradición legal e cultural do rural en Galicia, a casa familiar e as principais propiedades son herdadas pola filla máis vella, polo tanto o que cabería esperar é que os homes sempre fosen os que se desprazasen cara á casa familiar da muller.

A análise dos polimorfismos xenéticos neste tipo de poboacións debe reflectir estas estruturas sociais; deste xeito, nunha poboación cunha estrutura tipicamente matriarcal a diversidade do cromosoma Y (que é un marcador masculino) espérase que sexa moi elevada na poboación xeral pero cunha baixa variación entre os grupos poboacionais (neste caso as diferentes comarcas). Pola contra, nunha poboación cunha estrutura tipicamente patriarcal o que cabería esperar é unha elevada diversidade do ADN mitocondrial (que é un marcador feminino) na poboación xeral e unha baixa diferenciación entre grupos.

A modo comparativo analizouse tamén a poboación de Cantabria, situada no norte da Península lbérica e cunha extensión duns $5000 \mathrm{~km}^{2}$. A maioría dos 500000 habitantes que a forman viven 


\begin{tabular}{|cccc|}
\hline \multirow{2}{*}{ Cromosoma Y } & \multicolumn{2}{c}{ Estrutura poboacional } \\
\cline { 2 - 4 } & Diversidade & Patriarcal & Matriarcal \\
\cline { 2 - 4 } & Diferenzas entre grupos & Basa & Alta \\
\hline \multirow{2}{*}{ ADN me } & Diversidade & Ala & Baixa \\
\cline { 2 - 4 } & Duferenzas entre grupes & Raixa & Baisa \\
\cline { 2 - 4 } & &
\end{tabular}

nunha zona costeira plana e ben comunicada, distribuidos nas dúas principais cidades e en diversas vilas pequenas. Non obstante, o 20\% da poboación vive en áreas montañosas do interior, en aldeas de menos de 3000 habitantes, que de sempre tiveron moi malas comunicacións.

A análise realizouse dun xeito semellante á poboación galega, fixose un estudo de 150 individuos repartidos en tres comarcas diferentes e comprobouse que o seu patrón de diversidade era moi distinto ao de Galicia, neste caso habia grandes diferenzas entre as comarcas estudadas.

Como poderiamos explicar a uniformidade atopada en Galicia e as diferenzas atopadas en Cantabria?

A poboación galega, como xa dixeramos, estivo máis ou menos illada do resto de Iberia, en parte debido á meseta central española, que supoñía unha barreira co resto de España, e en parte debido factores politicos que a separaban de Portugal, pais co que estivo unida ata o século XI (Vázquez Varela, 1993). A pesar disto, como non foi detectada unha diferenciación do cromosoma $Y$ entre Galicia e outras partes da Península, nin dentro de Galicia, isto pode ser reflexo dun tamaño de poboación efectiva moi grande, de altos niveis de migración externa e interna, ou de ambos. En vista do historicamente documentado illamento, o tamaño de poboación efectiva grande e os movementos poboacionais internos deben de ser os factores máis importantes.

Pola contra, a xente dos vales montañosos de Cantabria mostrou unha diferenciación do cromosoma Y, probablemente debido ao illamento xeográfico a causa das montañas. Pero, ademais, neste caso o tamaño das poboacións ao longo da historia sempre foi máis pequeno e soamente a introdución do millo no século XVII permitiu a súa expansión (Brotons, 1992). 


\section{Estudo dos nuicleos urbanos}

No estudo de individuos pertencentes aos principais núcleos urbanos, ademais dos polimorfismos binarios e dos locus microsatélites, tamén se estudou a variabilidade do minisatélite MSY1, que, como xa se explicou, é o marcador máis variable presente no cromosoma $Y$, pero a súa variabilidade interna en forma de estruturas modulares dános a posibilidade de definir linaxes de cromosomas relacionados por descendencia.

A análise do MSY1 permitiunos identificar unha estrutura modular típica de poboacións norteafricanas, que aparecía na poboación galega cunha significativa frecuencia $(9,4 \%)$ e xamais fora identificada en ningunha outra mostra de procedencia europea. A presenza desta estrutura unicamente foi descrita en poboacións do Magreb, onde se atopa a unha frecuencia do $50 \%$, pero sempre en individuos do haplogrupo E3b (Brión et al., 2003). Na nosa poboación galega tamén foi descrita dentro do haplogrupo E3b, polo que podemos considerala como unha sublinaxe deste haplogrupo.

A presenza desta sublinaxe na comunidade galega podería ser explicada por diversas razóns, pero ningunha delas moi clara. Por un lado podería deberse a unha evolución converxente do minisatélite en ambas as dúas poboacións, é dicir, que o minisatélite evolucionase de xeito independente nas dúas poboacións $\mathrm{e}$ orixinase a mesma estrutura. Para comprobar se esta teoría era certa estudáronse, dentro desta subliñaxe, os STRs do cromosoma Y tanto na poboación galega como na norteafricana, co que se viu que estes polimorfismos estaban proximamente relacionados, de xeito que a probabilidade de que os individuos desta subliñaxe non estean relacionados é moi reducida.

Outra posible explicación á presenza da subliñaxe podería ser unha influencia árabe deixada no noroeste da Península xa que os árabes, maioritariamente homes, chegaron a Galicia no século vill e, aínda que o número foi reducido en comparación coa poboación autóctona, a acción estocástica de procesos evolutivos como a deriva xenética puido incrementar a frecuencia desta estrutura modular. 
Outra posible explicación que non podemos descartar sería a presenza dun fluxo xénico máis recente, ainda que non se coñecen datos de que Galicia recibise en tempos modernos unha influencia do norte de África, como puido ocorrer noutras rexións da Península Ibérica (núcleos urbanos do sur, do centro e do Mediterraneo).

Como vemos, os datos xenéticos non sempre resultan fáciles de interpretar en termos de eventos poboacionais, xa que moitas veces vense moi influenciados polos distintos modos de herdanza e as taxas de mutación dos diferentes marcadores empregados. É importante sublinar, para futuros estudos poboacionais, a necesidade de esclarecer as complexas relacións poboacionais e de realizar a análise de moitos marcadores xenéticos nun número significativo de mostras. 
Bosch, E., Calafell, F., Santos, FR., Pérez-Lezaun, A., Comas, D., Benchemsi, N., Tyler-Smith, C., Bertranpetit, J. (1999): "Variation in Short Tandem Repeats Is Deeply Structured By Genetic Background on the Human Y Chromosome". Am J Hum Genet 65: 1623-1638.

Brion, M., Salas, A., González-Neira, A., Lareu, M.V., Carracedo, A. (2003): "Insights into lberian population origins through the construction of highly informative Y-chromosome haplotypes using biallelic markers, STRs and the MSY1 minisatellite". Am J Phys Anthropol 122: 147-161.

Brotons, J.R. (1992): Guía de Cantabria. El País-Aguilar, Madrid.

Gusmão, L., Brión, M., González-Neira, A. (2000): "The human Y chromosome. Male-specific polymorphisms and forensic genetics". En M. J. Bogusz (ed.), Forensic Sciences. Handbook of Analytical Separation, vol. 2, Elsevier Science, Amsterdam, pp. 721-735.

Hurles, M.E., Irven, C., Nicholson, J., Taylor, P.G., Santos, F.R. Loughlin, J., Jobling, M.A., Sykes, B.C. (1998): "European Y-chromosomal lineages in Polynesians; a contrast to the population structure revealed by miDNA". Am J Hum Genet 65: 1437-1448.

Hurles, M.E., Veitia, R., Arroyo, E., Armenteros, M., Bertranpetit, J., Pérez-Lezaun, A., Bosch, E., Shlumukova, M., CambonThomsen, A., McElreavey, K., López de Munain, A., Röhl, A., Wilson, I.J., Singh, L., Pandya, A., Santos, F.R., TylerSmith, C., Jobling, M.A. (1999): "Recent male-mediated gene flow over a linguistic barrier in lberia, suggested by analysis of a Y-chromosomal DNA polymorphism". Am J Hum Genet 65: 1437-1448.

Jobling, M.A. e Tyler-Smith, C. (1995): "Fathers and sons: the Y chromosome and human evolution". Trends Genet 11: 449456. 
Jobling, M.A. e Tyler-Smith, C. (2003): "The human Ychromosome: an evolutionary marker comes of age". Nat. Rev. Genet. 4(8): 598-612.

Jobling, M.A., Bouzekri, N. e Taylor, P.G. (1998): "Hypervariable digital DNA codes for human paternal lineages: MVR-PCR at the Y-specific minisatellite MSY1 (DIF155S1)". Hum Mol Genet 7: 643-653.

The $Y$ chromosome consortium (2002): "A Nomenclature system for the tree of human Y-chromosomal binary haplogroups". Genome Res. 12: 339-348.

Underhill, P.A., Shen P., Lin, A.A., Jin, L., Passarino, G., Yang, WH., Kauffman, E., Bonné-Tamir, B., Bertranpetit, J., Francalacci, P., Ibrahim, M., Jenkins, T., Kidd, J.R., Mehdi, S.Q., Seielstad, M.T., Wells, R.S., Piazza, A., Davis, R.W., Feldman, M.W., Cavalli--Sforza, L.L., Oefner, P.J. (2000): "Y chromosome sequence variation and the history of human populations". Nature Genetics 26: 358-361.

Vãzquez Varela, J.M. (coord.) (1993): "Das Orixes ó Castrexo". Galicia. Historia. Tomo I: Prehistoria e historia antiga. Hércules Ediciones, A Coruña. 